\title{
Increasing Divergence in Drug Prices Between the United States and Germany After Implementation of Comparative Effectiveness Analysis and Collective Price Negotiations
}

\author{
Fabian Berkemeier, MS; Christopher Whaley, PhD; and James C. Robinson, PhD
}

\begin{abstract}
BACKGROUND: Payers and purchasers in the United States seek to moderate drug prices and align them with the incremental clinical benefit offered by individual medications; some policymakers have proposed linking U.S. prices to an index of prices paid in other nations. The German health care system resembles that of the United States in featuring multiple private payers but differs in featuring a highly coordinated process of comparative clinical assessment and price negotiations for drugs.
\end{abstract}

OBJECTIVES: To (a) measure trends in prices paid for physician-administered drugs in Germany before and after the mandate for comparative effectiveness assessment and price negotiations in 2011 and (b) compare them with price trends for the same drugs in the United States.

METHODS: This study observed trends in the prices paid for 80 physicianadministered drugs, which account for approximately half of Medicare Part B drug spending. Quarterly data covering 2004-2018 were obtained for Germany from the Lauer-Taxe database, which contains net prices paid by all German payers. U.S. data were obtained from the Centers for Medicare \& Medicaid Services, which publishes net prices paid by private U.S. payers and the Medicare Part B program. These data contain the net prices actually paid after accounting for all discounts and rebates, not merely the manufacturer's list price. Statistical analyses were conducted with multivariable difference-in-differences regression methods.

RESULTS: Before implementation in Germany of comparative effectiveness analysis and collective price negotiations, net U.S. prices for physicianadministered drugs averaged $29.2 \%$ higher $(95 \% \mathrm{Cl}=26.6 \%-31.7)$ than those in Germany. After implementation of comparative effectiveness assessments and price negotiations in 2011, the divergence between U.S. and German prices increased another $28.9 \%(95 \% \mathrm{Cl}=23.7 \%-34.3 \%)$.

CONCLUSIONS: Commercial health insurers and Medicare pay significantly higher net prices for physician-administered drugs than do insurers in Germany, with the divergence growing after the mandate in Germany that new drugs be subject to comparative effectiveness assessment and collective price negotiations. The experience of Germany may be of special value for the current U.S. debate over pharmaceutical pricing reform, given the demographic, economic, and health system similarities between the 2 nations.

J Manag Care Spec Pharm. 2019;25(12):1310-17

Copyright $\odot 2019$, Academy of Managed Care Pharmacy. All rights reserved.

\section{What is already known about this subject}

The United States is currently engaged in a bipartisan search for a new drug assessment and pricing structure for Medicare and private insurers.

In 2011, the German health care system adopted mandatory comparative clinical assessment and a structure of collective price negotiations between health insurers and pharmaceutical manufacturers.

- Spending on pharmaceuticals and other components of health care is substantially lower in Germany than in the United States, despite demographic and economic similarities between the 2 nations.

\section{What this study adds}

The German system of drug effectiveness assessment and price negotiations seeks to constrain prices at the time of initial market availability and prohibits subsequent price increases unless supported by new evidence of effectiveness.

In the 5 years before 2011, when comparative effectiveness analysis and collective price negotiations were mandated in Germany, U.S. prices for physician-administered drugs averaged $29.2 \%$ higher than those in Germany.

The divergence between U.S. and German prices increased another 28.9\% between 2012 and 2018 .

$\mathrm{I}^{\mathrm{n}}$ $\mathrm{n}$ the United States, prices for physician-administered drugs are established unilaterally by manufacturers, who then offer discounts and rebates to distributors and other intermediaries. Observers have criticized this manufacturerled process as contributing to the high net prices paid in the United States compared with those in nations that rely on more formalized clinical assessment and price negotiations. ${ }^{1}$ As part of efforts to reduce international disparities in drug prices, the Trump administration has proposed a "reference pricing" initiative whereby payments under Medicare Part B would be linked to an index of prices paid in other high-income nations, ${ }^{2}$ estimating that in 2018 Medicare spent 47\% more for 27 of these drugs than if it had paid prices linked to the index. ${ }^{3}$

In assessing the potential effect of policy initiatives to address drug prices, it is useful to consider the experience 
of Germany, a large and prosperous nation whose insurance system is composed of 158 independent insurers (mostly referred to as "sickness funds") rather than the public singlepayer structure found in most high-income nations. In 2011, Germany mandated that new drugs be subject to comparative effectiveness assessment by an organization representing the nation's insurers, physicians, hospitals, and patient advocacy organizations and that these analyses be used by the insurers to collectively negotiate prices with manufacturers. ${ }^{4-6}$ This publicly authorized but privately managed system was designed to replace the previous regulatory framework, where rebates had been mandated uniformly to all drugs regardless of their clinical benefits.

This study calculated trends in prices for physician-administered drugs between 2004 and 2018 in Germany and the United States. The study used data on the actual prices paid for each drug in each quarter, accounting for all discounts and rebates in each nation. Germany publishes net drug prices in the Lauer-Taxe database. ${ }^{7}$ U.S. pharmaceutical manufacturers are required to report to Medicare the average price they are paid by private payers, also net of discounts and rebates. Medicare pays this average net price for physician-administered drugs reimbursed under Part B, referred to as the average sales price (ASP). Published ASP data thus represent the actual prices paid by Medicare and the average of actual prices paid by private U.S. insurers. The data used in this study reflect the amounts collected by pharmaceutical manufacturers from payers and do not include any markup to physicians for the handling and management of the drugs (e.g., the 6\% buy-andbill supplement paid to U.S. physicians).

\section{Methods}

\section{The German System for Establishing Drug Prices}

The German health care financing system is based on 110 sickness funds, which collectively cover health care expenses for $90 \%$ of the population, supplemented by 48 indemnity insurance firms that cover the remainder, for a total of 158 private payers. In Germany, there are no public programs analogous to Medicare and Medicaid in the United States. The sickness funds are subject to extensive regulation and subsidies by the federal and state governments; the indemnity insurers are subject to less regulation but enjoy fewer subsidies. ${ }^{8}$

The German pharmaceutical pricing system builds on this multipayer insurance system. Manufacturers set prices at the time of market launch subject to mandatory rebates that have varied across years, depending on the pressure exerted by drug spending on the federal and state budgets. Before 2011, the rebates were uniform (in percentage terms) across drugs, regardless of the clinical benefit offered by each product.

In 2011, Germany created a policy framework to align the price of newly launched drugs with each product's comparative clinical benefit. Consequently, drugs authorized for market launch by the European Medicines Agency (EMA) were subject to comparative clinical assessment by the Federal Joint Committee (GBA), a quasi-public entity representing the principal payer and provider organizations., ${ }^{5,9}$ The GBA commissions an evaluation of a new product's clinical benefit relative to the most comparable product for the targeted indication from the Institute for Quality and Efficiency in Healthcare. The GBA then combines these reports with testimony in public hearings from manufacturers, patient advocacy groups, and physician associations and makes an official assessment of the new drug's incremental contribution for each clinical indication. ${ }^{10}$

The umbrella organization of sickness funds (GKV-SV) then negotiates a price with the manufacturer based on the GBA assessment, the market price of the comparator drug, the prices of other drugs used to treat the same condition, and the prices charged by the manufacturer for its new drug in other European markets. ${ }^{11}$ Between the implementation of the new negotiations process in 2011 through the first quarter of 2019, the net negotiated prices averaged $23.6 \%$ below the manufacturers' list prices. ${ }^{12}$

The price negotiations are structured as a bilateral monopoly, with a single purchaser facing a single seller, since all sickness funds and indemnity insurers will pay the same price for the same product. If no agreement can be negotiated, the drug's price is established by an arbitration panel consisting of representatives from each side, plus an appointed neutral chair. The new price takes effect 1 year after the drug's initial market launch, replacing the original list price. ${ }^{11}$

Prices for drugs launched before 2011 were not subject to clinical assessments by the GBA and price negotiations by the GKV-SV. These products were paid their list price net of a uniform mandatory rebate that has fluctuated over the years based on the legislators' and regulators' views of drug spending relative to trends in overall economic growth. The mandatory rebate was 6\% until August 2010, when it was increased to 16\%. Since 2014, the uniform mandatory rebate has been set at $7 \%$.

German law prohibits the manufacturer from unilaterally increasing a drug's price after the initial negotiations with payers. Prices can be renegotiated if the GBA subjects the product to a reassessment of its comparative clinical benefit. Since 2011, a total of 231 drugs have been assessed by the GBA when they first came on the market, and 75 drugs have had their clinical benefits reassessed and prices renegotiated at least once. ${ }^{13}$ These figures include patient self-administered drugs, as well as the physician-administered drugs included in this study.

\section{The Medicare System for Establishing Drug Prices}

Since implementation of the Medicare Modernization Act, the Centers for Medicare \& Medicaid Services (CMS) has required manufacturers of physician-administered drugs covered under 
Medicare Part B to report net prices after adjusting for discounts and rebates negotiated with private health insurers, pharmacy benefit managers (PBMs), wholesalers, specialty distributors, physician practices, hospitals, and other purchasers. ${ }^{14} \mathrm{CMS}$ uses these reports to calculate an ASP for each drug, which it then uses to pay for medications under Part B. The ASP thus represents the price paid by Medicare and the average of the net prices paid by private purchasers. It does not reflect the prices paid by state Medicaid programs and other federal programs, such as the Veterans Administration, which are eligible for various mandated discounts that do not enter the ASP calculation.

\section{Data on Drug Prices}

This study included physician-administered drugs that were newly authorized for market access and available for physician prescription in Germany and the United States between 2004 and 2018. We used the prices paid by the purchasers, net of all discounts and rebates, rather than the manufacturers' list prices. Net prices are available for the German market through the Lauer-Taxe database and for the U.S. market through CMS.,15

We matched prices for physician-administered drugs covered by the German sickness funds and Medicare Part B from the third quarter of 2004, the first quarter for which ASP data are available, through the second quarter of 2018. The number of quarters represented by each drug in the database depends on when the drug was first reimbursed by the payers and available for prescription by physicians. In Germany, drugs are priced and available for prescription immediately after market introduction. In the United States, calculation of ASP by CMS lags 2 quarters after initial market access to incorporate the discounts and rebates offered by manufacturers to private payers and intermediaries. In our statistical analysis, we adjusted for the number of quarters in which each drug is available for use. We removed quarterly observations for drugs that were available for prescription in only 1 of the 2 nations. The Appendix presents the criteria by which drugs were selected for study inclusion (available in online article).

Our analytic database includes 4,016 quarters of price data on 80 physician-administered drugs launched between January 2004 and July 2018. Of these, 37 drugs had been launched after 2011 and were subject in Germany to GBA comparative benefit assessment and GKV-SV price negotiations. For the 43 remaining drugs, the German price was the manufacturer's list price, net of mandated rebates. The most recent publicly available data on Medicare Part B spending per drug is for 2017. Medicare price data are available through 2018, but spending data, which reflect volume as well as price, are only available through 2017. Spending figures were available for 58 of the 80 drugs; together, they accounted for $48 \%$ of Part B drug spending in that year. ${ }^{16}$

\section{Statistical Methods}

For our univariate descriptive statistics, we calculated the U.S. and German prices for each drug plus the ratio of those prices in the quarter when the drug was first available in each nation and in the quarter for which data were most recently available. We only included each drug in our analysis for the quarters during which it was available for prescription in both the United States and Germany.

Medicare calculates each drug's ASP for each quarter using net prices charged to private insurers 2 quarters previously. Because our focus was on net prices charged to private U.S. insurers, we used the published ASP from 2 quarters later as each drug's price for each quarter. We converted German package sizes into those reported in the Medicare Part B data. German prices per drug then were converted to U.S. dollars using purchasing power conversion rates published by the Organisation for Economic Co-operation and Development. ${ }^{17}$ The quarterly U.S. and German prices were adjusted to 2018 dollars using the U.S. Bureau of Labor Statistics BLS CPI-urban index. ${ }^{18}$ We obtained the 2017 Medicare Part B expenditures for each drug as an indicator of the relative economic importance of each product.

To identify the association between U.S. and German prices, on the one hand, and the adoption of comparative effectiveness assessment and collective negotiations in Germany, on the other, we conducted multivariable difference-in-differences regressions. Difference-in-differences methods replicate the effect of randomization in data obtained from controlled trial settings for observational data. ${ }^{19}$ They use data from a setting where the intervention did not happen (in this case the United States did not implement comparative effectiveness analysis and collective price negotiations) as a comparison group for data from the setting where the intervention did happen (in this case Germany). This statistical method used the U.S. prices (which are not based on comparative effectiveness assessment and collective negotiations) as the comparison group for assessing changes in German prices.

The multivariable regressions include covariates for each drug and each quarter to adjust for differences in characteristics of the drugs and for the effect of seasonal factors that would affect U.S. and German prices similarly. The regressions include an interaction term between the covariate that distinguishes quarters before and after 2011 and the covariate that distinguishes the U.S. price from the German price, as is standard in difference-in-differences regressions. These regressions used the log-transformed price in each country as an outcome variable to reduce sensitivity to outlier drugs that had particularly large price differences across the 2 nations and to measure the change over time in percentage terms. 
Increasing Divergence in Drug Prices Between the United States and Germany After Implementation of Comparative Effectiveness Analysis and Collective Price Negotiations

TABLE 1 U.S. and German Prices and Medicare Part B Expenditures for Drugs Administered by Physicians

\begin{tabular}{|c|c|c|c|c|c|c|c|c|c|}
\hline \multirow[b]{2}{*}{ Brand Name of Drug } & \multicolumn{4}{|c|}{ First Matched Price Data } & \multicolumn{4}{|c|}{ Final Matched Price Data } & \multirow{2}{*}{$\begin{array}{c}\text { Medicare } \\
\text { Part B } \\
\text { Expenditures } \\
2017, \$\end{array}$} \\
\hline & $\begin{array}{c}\text { Calendar } \\
\text { Quarter }\end{array}$ & $\begin{array}{l}\text { U.S. Price } \\
\text { Per Bill Unit }\end{array}$ & $\begin{array}{c}\text { DE Price } \\
\text { Per Bill Unit }\end{array}$ & $\begin{array}{c}\text { U.S./DE } \\
\text { Price Ratio }\end{array}$ & $\begin{array}{l}\text { Calendar } \\
\text { Quarter }\end{array}$ & $\begin{array}{c}\text { U.S. Price } \\
\text { Per Bill Unit }\end{array}$ & $\begin{array}{c}\text { DE Price } \\
\text { Per Bill Unit }\end{array}$ & $\begin{array}{c}\text { U.S./DE } \\
\text { Price Ratio }\end{array}$ & \\
\hline Erbitux & $3 Q 2004$ & 65.98 & 28.28 & 2.33 & 2Q2018 & 60.63 & 27.67 & 2.19 & $203,518,737$ \\
\hline Alimta & 4Q2004 & 53.89 & 41.20 & 1.31 & 2Q2018 & 68.22 & 41.67 & 1.64 & $474,954,415$ \\
\hline Avastin & $1 Q 2005$ & 73.42 & 41.98 & 1.75 & 2Q2018 & 79.25 & 39.88 & 1.99 & $1,066,675,107$ \\
\hline Kepivance & 4Q2005 & 14.72 & 8.86 & 1.66 & 2Q2018 & 20.29 & 7.92 & 2.56 & 542,655 \\
\hline Macugen & 2Q2006 & 1313.70 & 896.98 & 1.46 & 2Q2018 & 713.86 & 812.96 & 0.88 & NA \\
\hline Naglazyme & $3 Q 2006$ & 377.16 & 411.23 & 0.92 & 2Q2018 & 389.95 & 368.75 & 1.06 & NA \\
\hline Tysabri & 3Q2006 & 9.61 & 8.34 & 1.15 & 2Q2018 & 19.83 & 7.84 & 2.53 & $300,729,996$ \\
\hline Tygacil & 3Q2006 & 1.13 & 1.35 & 0.84 & 2Q2018 & 2.06 & 1.29 & 1.60 & $1,320,870$ \\
\hline Prialt & 3Q2006 & 8.07 & 5.24 & 1.54 & 2Q2018 & 7.59 & 4.71 & 1.61 & $6,181,592$ \\
\hline Clolar (U.S.)/Evoltra (DE) & 4Q2006 & 145.41 & 122.95 & 1.18 & 2Q2018 & 111.29 & 111.43 & 1.00 & $2,512,413$ \\
\hline Lumizyme (U.S.)/Myozyme (DE) & 3Q2007 & 154.05 & 147.33 & 1.05 & 2Q2018 & 163.83 & 136.12 & 1.20 & $66,141,626$ \\
\hline Elaprase & 3Q2007 & 551.08 & 631.01 & 0.87 & 2Q2018 & 536.56 & 599.52 & 0.89 & $1,468,256$ \\
\hline Orencia & $3 Q 2007$ & 22.63 & 22.93 & 0.99 & 2Q2018 & 52.93 & 21.72 & 2.44 & $700,099,533$ \\
\hline Lucentis & $3 Q 2007$ & 491.56 & 68.54 & 7.17 & 2Q2018 & 373.36 & 53.28 & 7.01 & $1,037,747,584$ \\
\hline Arranon (U.S.)/Atriance (DE) & 4Q2007 & 111.04 & 89.59 & 1.24 & 2Q2018 & 152.21 & 81.92 & 1.86 & $\mathrm{NA}$ \\
\hline Eraxis (U.S.)/Ecalta (DE) & 4Q2007 & 1.85 & 5.90 & 0.31 & 2Q2018 & 0.54 & 5.47 & 0.10 & $\mathrm{NA}$ \\
\hline Soliris & 4Q2007 & 213.61 & 206.89 & 1.03 & 2Q2018 & 230.48 & 192.71 & 1.20 & $311,737,718$ \\
\hline Vectibix & 1Q2008 & 95.30 & 53.86 & 1.77 & 2Q2018 & 114.38 & 60.43 & 1.89 & $88,775,240$ \\
\hline Abilify & 3Q2008 & 0.33 & 0.16 & 2.06 & 1Q2016 & 0.79 & 0.15 & 5.27 & $\mathrm{NA}$ \\
\hline Somatuline & $3 Q 2008$ & 31.31 & 21.35 & 1.47 & 2Q2018 & 58.84 & 21.65 & 2.72 & $152,026,957$ \\
\hline Torisel & 3Q2008 & 55.87 & 37.55 & 1.49 & 2Q2018 & 73.75 & 37.00 & 1.99 & $16,034,715$ \\
\hline Emend (U.S.)/Ivemend (DE) & $3 Q 2008$ & 1.83 & 0.33 & 5.55 & 2Q2018 & 2.19 & 0.32 & 6.84 & $93,740,803$ \\
\hline Mycamine & 1Q2009 & 1.31 & 6.66 & 0.20 & 2Q2018 & 0.89 & 6.08 & 0.15 & 243,256 \\
\hline Vidaza & 1Q2009 & 5.57 & 4.51 & 1.24 & 2Q2018 & 1.47 & 4.45 & 0.33 & $88,774,274$ \\
\hline Eovist (U.S.)/Primovist (DE) & 3Q2009 & 15.81 & 22.31 & 0.71 & 2Q2018 & 14.83 & 23.21 & 0.64 & 896,875 \\
\hline Nplate & 3Q2009 & 51.03 & 33.27 & 1.53 & 2Q2018 & 71.40 & 31.61 & 2.26 & $209,220,872$ \\
\hline Firmagon & 3Q2009 & 3.36 & 1.44 & 2.33 & 2Q2018 & 3.72 & 1.31 & 2.84 & $17,886,201$ \\
\hline Mozobil & 3Q2009 & 314.52 & 315.07 & 1.00 & 2Q2018 & 330.41 & 291.31 & 1.13 & $21,325,157$ \\
\hline Cimzia & 4Q2009 & 4.43 & 4.20 & 1.05 & 2Q2018 & 8.14 & 3.83 & 2.13 & $305,139,039$ \\
\hline Doribax & 2Q2010 & 0.63 & 0.71 & 0.89 & 1Q2016 & 0.81 & 0.62 & 1.31 & 33,286 \\
\hline Ablavar (U.S.)/Vasovist (DE) & $3 Q 2010$ & 14.74 & 16.36 & 0.90 & 1Q2012 & 13.23 & 16.34 & 0.81 & $\mathrm{NA}$ \\
\hline Stelara & 3Q2010 & 128.84 & 55.07 & 2.34 & 2Q2018 & 191.03 & 38.55 & 4.96 & $92,959,948$ \\
\hline Actemra (U.S.)/RoActemra (DE) & 3Q2010 & 4.00 & 2.87 & 1.40 & 2Q2018 & 4.73 & 2.69 & 1.76 & $211,708,975$ \\
\hline Ilaris & $3 Q 2010$ & 102.69 & 91.52 & 1.12 & 2Q2018 & 111.00 & 90.74 & 1.22 & $\mathrm{NA}$ \\
\hline Arzerra & 3Q2010 & 52.26 & 31.49 & 1.66 & 2Q2018 & 58.55 & 31.19 & 1.88 & $12,365,431$ \\
\hline Vpriv & 4Q2010 & 402.91 & 549.07 & 0.73 & 2Q2018 & 345.39 & 565.49 & 0.61 & $24,856,390$ \\
\hline Xiaflex (U.S.)/Xiapex (DE) & 2Q2011 & 41.88 & 11.62 & 3.60 & 3Q2012 & 41.03 & 11.41 & 3.60 & $41,814,444$ \\
\hline Lexiscan (U.S.)/Rapiscan (DE) & 2Q2011 & 58.28 & 23.25 & 2.51 & 2Q2018 & 56.56 & 23.25 & 2.43 & $126,791,153$ \\
\hline Prolia & 3Q2011 & 16.11 & 4.72 & 3.41 & 2Q2018 & 18.58 & 4.91 & 3.78 & $1,238,722,483$ \\
\hline Yervoy & 3Q2011 & 139.60 & 101.06 & 1.38 & 2Q2018 & 150.87 & 78.75 & 1.92 & $261,446,036$ \\
\hline Halaven & 3Q2011 & 100.53 & 54.04 & 1.86 & 2Q2018 & 114.34 & 45.36 & 2.52 & $56,342,539$ \\
\hline Benlysta & 3Q2011 & 42.89 & 22.05 & 1.95 & 2Q2018 & 44.16 & 14.44 & 3.06 & $85,483,996$ \\
\hline Jevtana & 3Q2011 & 150.93 & 87.09 & 1.73 & 2Q2018 & 167.99 & 65.74 & 2.56 & $92,640,872$ \\
\hline Nulojix & 3Q2012 & 4.16 & 2.94 & 1.41 & 2Q2018 & 3.81 & 2.36 & 1.61 & $36,434,031$ \\
\hline Adcetris & 4Q2012 & 108.02 & 92.61 & 1.17 & 2Q2018 & 150.48 & 76.72 & 1.96 & $92,352,212$ \\
\hline Eylea & 1Q2013 & 1056.89 & 288.95 & 3.66 & 2Q2018 & 967.33 & 266.24 & 3.63 & $2,465,832,792$ \\
\hline Zaltrap & 3Q2013 & 10.10 & 4.78 & 2.11 & 2Q2018 & 8.32 & 3.99 & 2.09 & $3,925,386$ \\
\hline Perjeta & 3Q2013 & 11.01 & 8.65 & 1.27 & 2Q2018 & 11.87 & 6.95 & 1.71 & $228,165,414$ \\
\hline Jetrea & 3Q2013 & 1128.30 & 899.27 & 1.25 & 2Q2018 & 836.34 & 805.28 & 1.04 & $1,788,814$ \\
\hline Simponi & 4Q2013 & 25.75 & 33.38 & 0.77 & 2Q2018 & 24.01 & 20.68 & 1.16 & $229,811,823$ \\
\hline
\end{tabular}




\begin{tabular}{|c|c|c|c|c|c|c|c|c|c|}
\hline \multirow[b]{2}{*}{ Brand Name of Drug } & \multicolumn{4}{|c|}{ First Matched Price Data } & \multicolumn{4}{|c|}{ Final Matched Price Data } & \multirow{2}{*}{$\begin{array}{c}\text { Medicare } \\
\text { Part B } \\
\text { Expenditures } \\
2017, \$\end{array}$} \\
\hline & $\begin{array}{l}\text { Calendar } \\
\text { Quarter }\end{array}$ & $\begin{array}{c}\text { U.S. Price } \\
\text { Per Bill Unit }\end{array}$ & $\begin{array}{c}\text { DE Price } \\
\text { Per Bill Unit }\end{array}$ & $\begin{array}{c}\text { U.S./DE } \\
\text { Price Ratio }\end{array}$ & $\begin{array}{l}\text { Calendar } \\
\text { Quarter }\end{array}$ & $\begin{array}{c}\text { U.S. Price } \\
\text { Per Bill Unit }\end{array}$ & $\begin{array}{c}\text { DE Price } \\
\text { Per Bill Unit }\end{array}$ & $\begin{array}{c}\text { U.S./DE } \\
\text { Price Ratio }\end{array}$ & \\
\hline Kadcyla & 1Q2014 & 30.91 & 26.40 & 1.17 & 2Q2018 & 30.78 & 20.00 & 1.54 & $115,989,170$ \\
\hline Gazyva (U.S.)/Gazyvaro (DE) & 3Q2014 & 57.53 & 50.93 & 1.13 & 2Q2018 & 62.63 & 39.77 & 1.57 & $81,218,385$ \\
\hline Vibativ & $3 Q 2014$ & 5.08 & 14.24 & 0.36 & 2Q2018 & 5.47 & 13.73 & 0.40 & $1,901,762$ \\
\hline Provenge & 4Q2014 & 38058.17 & 34486.07 & 1.10 & 1Q2016 & 39794.29 & 34030.23 & 1.17 & $202,485,909$ \\
\hline Rixubis & 2Q2015 & 1.31 & 1.31 & 1.00 & 2Q2018 & 1.30 & 1.28 & 1.02 & $11,155,671$ \\
\hline Novoeight & $3 Q 2015$ & 1.54 & 1.13 & 1.36 & 2Q2018 & 1.34 & 1.10 & 1.22 & $8,425,319$ \\
\hline Entyvio & $3 Q 2015$ & 18.04 & 11.60 & 1.55 & 2Q2018 & 19.58 & 8.33 & 2.35 & $182,585,694$ \\
\hline Opdivo & $3 Q 2015$ & 26.88 & 18.05 & 1.49 & 2Q2018 & 27.54 & 12.82 & 2.15 & $1,470,525,369$ \\
\hline Keytruda & $3 Q 2015$ & 48.41 & 45.22 & 1.07 & 2Q2018 & 49.35 & 32.46 & 1.52 & $1,033,716,693$ \\
\hline Cyramza & $3 Q 2015$ & 57.23 & 37.78 & 1.51 & 2Q2018 & 57.68 & 21.04 & 2.74 & $105,936,795$ \\
\hline Sivextro & $3 Q 2015$ & 1.29 & 1.56 & 0.83 & 2Q2018 & 1.43 & 1.53 & 0.93 & NA \\
\hline Kyprolis & $1 Q 2016$ & 33.26 & 28.26 & 1.18 & 2Q2018 & 36.32 & 19.48 & 1.86 & $252,997,460$ \\
\hline Eloctate (U.S.)/Elocta (DE) & 1Q2016 & 1.98 & 1.84 & 1.08 & 2Q2018 & 2.01 & 1.25 & 1.61 & $66,846,665$ \\
\hline Darzalex & $3 Q 2016$ & 49.09 & 71.22 & 0.69 & 2Q2018 & 52.41 & 52.09 & 1.01 & NA \\
\hline Alprolix & $3 Q 2016$ & 3.06 & 2.99 & 1.02 & 2Q2018 & 2.99 & 1.95 & 1.53 & $52,381,845$ \\
\hline Empliciti & 3Q2016 & 6.51 & 4.98 & 1.31 & 2Q2018 & 6.42 & 3.79 & 1.69 & NA \\
\hline Portrazza & $3 Q 2016$ & 5.50 & 2.34 & 2.35 & 2Q2018 & 5.57 & 0.70 & 7.96 & NA \\
\hline Imlygic & 3Q2016 & 48.26 & 30.36 & 1.59 & 2Q2018 & 49.99 & 15.10 & 3.31 & NA \\
\hline Dalvance (U.S.)/Xydalba (DE) & $4 Q 2016$ & 15.41 & 10.35 & 1.49 & 2Q2018 & 14.35 & 10.11 & 1.42 & $18,537,824$ \\
\hline Blincyto & 1Q2017 & 104.80 & 92.73 & 1.13 & 2Q2018 & 110.37 & 72.67 & 1.52 & $9,838,903$ \\
\hline Ruconest & 2Q2017 & 28.67 & 5.93 & 4.83 & 2Q2018 & 27.65 & 5.81 & 4.76 & NA \\
\hline Lartruvo & 3Q2017 & 51.17 & 38.75 & 1.32 & 2Q2018 & 51.04 & 31.42 & 1.62 & NA \\
\hline Tecentriq & 4Q2017 & 77.83 & 54.05 & 1.44 & 2Q2018 & 76.91 & 52.94 & 1.45 & NA \\
\hline Bavencio & 4Q2017 & 82.60 & 57.70 & 1.43 & 2Q2018 & 81.82 & 56.52 & 1.45 & $\mathrm{NA}$ \\
\hline OcrevU.S. & 1Q2018 & 57.17 & 27.84 & 2.05 & 2Q2018 & 57.34 & 27.84 & 2.06 & NA \\
\hline Idelvion & 2Q2018 & 4.28 & 2.66 & 1.61 & 2Q2018 & 4.28 & 2.66 & 1.61 & NA \\
\hline Nucala & 2Q2018 & 29.58 & 13.84 & 2.14 & 2Q2018 & 29.58 & 13.84 & 2.14 & NA \\
\hline Cinqair (U.S.)/Cinqaero (DE) & 2Q2018 & 9.30 & 5.72 & 1.63 & 2Q2018 & 9.30 & 5.72 & 1.63 & NA \\
\hline Hemlibra & 2Q2018 & 48.86 & 50.70 & 0.96 & 2Q2018 & 48.86 & 50.70 & 0.96 & NA \\
\hline Adynovate (U.S.)/Adynovi (DE) & 2Q2018 & 1.72 & 1.56 & 1.10 & 2Q2018 & 1.72 & 1.56 & 1.10 & $\mathrm{NA}$ \\
\hline
\end{tabular}

\section{Results}

Table 1 presents data on the 80 physician-administered drugs that were newly available for physician prescription between 2004 and 2018 in both the United States and Germany. The first column gives the brand name and the second/sixth columns the year and quarter in which price data for the drug were first available in both nations. The third and fourth columns present each drug's price per dosage unit in the United States and Germany. The fifth column gives the ratio of the U.S. to the German price. The seventh and eighth columns present each drug's U.S. and German price in the most recent quarter, and the ninth column presents their ratios. For most of the drugs, the most recent quarter on the market was the second quarter of 2018, but 5 drugs were removed from either the U.S. or the German drug market in an earlier quarter. The tenth column presents Medicare Part B spending on each drug in 2017, the most recent year for which spending data are available. In that year, the 58 drugs with available expenditure data accounted for $\$ 14.1$ billion, $47.8 \%$ of total Medicare Part B drug spending in that year.

As indicated in Table 1, the ratio of U.S. to German prices in the first quarter with price data ranged from 0.2 to 7.2 , with a median of 1.34. Of the 80 drugs in our study, 57 experienced subsequent price increases in the United States relative to Germany in the years after launch, with a median increase of 44 percentage points. Eighteen drugs experienced a decline in the U.S. to Germany price difference, with a median reduction of 11 percentage points. Five drugs had prices in both nations for only 1 quarter so had no opportunity to experience a price change. The changes in price ratios were due to the greater 


\begin{tabular}{|c|c|c|}
\hline TABLE 2 & \multicolumn{2}{|c|}{$\begin{array}{l}\text { Growth in the U.S. to German Drug } \\
\text { Price Difference After Implementation } \\
\text { of Comparative Clinical Assessment and } \\
\text { Price Negotiations After } 2011\end{array}$} \\
\hline seline U.S. pri & remium $(95 \% \mathrm{CI})$ & $\begin{array}{c}29.2 \% \\
(26.6 \%-31.8 \%)^{a}\end{array}$ \\
\hline $\begin{array}{l}\text { Change in U.S. pric } \\
\text { 2011 AMNOG intrc }\end{array}$ & $\begin{array}{l}\text { premium following } \\
\text { luction }(95 \% \mathrm{CI})\end{array}$ & $\begin{array}{c}28.9 \% \\
(23.7 \%-34.3 \%)^{b} \\
\end{array}$ \\
\hline \multicolumn{3}{|c|}{$\begin{array}{l}a P<0.05 . \\
b P<0.01 . \\
\text { AMNOG=German law relating to the marketing of pharmaceutical products in } \\
\text { Germany; CI= confidence interval. }\end{array}$} \\
\hline
\end{tabular}

number of increases in the United States and decreases in Germany. Of the drugs that increased prices in United States, the average increase from the quarter first on the market to 2018 was 26\%. These drugs experienced an average 15\% price decrease in Germany during the same period. Of the drugs that decreased prices in the United States, the average decrease from the quarter first on the market to 2018 was 16\%. These drugs experienced an average $9 \%$ price decrease in Germany during the same period. By the second quarter of 2018, the median net price paid in the United States was 63\% above the net price level paid in Germany.

Table 2 presents the results of multivariable difference-indifferences regressions that identify the association between U.S. and German prices, on the one hand, and the 2011 implementation of comparative effectiveness analysis and collective price negotiations in Germany, on the other. The average price ratio before 2011 was 29.2\% (95\% confidence interval $[\mathrm{CI}]=26.6 \%-31.8 \%$ ). This pre-2011 difference was due to factors aside from comparative effectiveness analysis and collective price negotiations, which were only introduced in 2011. The causes for the difference could include the uniform rebates mandated in Germany and the restriction there on price increases after launch. In the years after implementation of comparative effectiveness assessment and price negotiations, the difference between U.S. and German prices rose another 28.9\% (95\% CI =23.7\%-34.3\%).

\section{Discussion}

Currently in the United States, there is an active debate over how to moderate the growth in drug prices and to better align the price of each medication with its comparative clinical benefit. Germany's experience offers especially valuable insights. Since 2011, Germany has required that all new drugs be subject to comparative effectiveness assessment and that the results of these analyses be used as the basis of price negotiations between the manufacturer and the association of health insurers. Germany prohibits subsequent price increases unless a new comparative effectiveness analysis is conducted and a new price is negotiated.
As reported in this study, the German system has been more successful than its U.S. counterpart in moderating price increases, especially since the 2011 policy changes. We examined trends in prices for physician-administered (typically infused or injected) drugs that were newly launched and available for prescription between 2004 and 2018. Before 2011, U.S. prices averaged 29.2\% higher than their German counterparts. After 2011, the divergence grew an additional 28.9 percentage points.

\section{Limitations}

The findings of this study should be assessed in light of its limitations. Trends in U.S. drug prices were compared with those in only 1 other nation, albeit one with approximately similar income and multipayer financing system and subject to considerably more regulation than in the United States. Comparative data were only available on drugs administered by physicians covered by Medicare Part B. CMS does not make available net price data for patient self-administered drugs covered under Medicare Part D, and prices net of rebates are not obtainable from private insurers for Part D drugs.

This study reported a significant strengthening of the German drug purchasing approach, measured relative to its U.S. counterpart, after the pharmaceutical policy reforms of 2011. Our study was not able to distinguish the separate effects of comparative effectiveness analysis, on the one hand, and price negotiations, on the other, since they were implemented simultaneously.

\section{Implications for U.S. Pharmaceutical Policy Reform}

The record of price moderation in Germany is remarkable given that it has been achieved without reliance on the tools used most commonly to obtain discounts and rebates in the United States. Narrow insurer drug formularies in the United States require physicians to modulate their prescribing according to the formulary developed by each patient's insurance plan or PBM. Prior authorization and step therapy policies impose substantial administrative burdens on physicians and patients. High consumer cost sharing impedes patient compliance and adherence and imposes significant financial burdens on patients who do comply with their physicians' prescriptions.

In contrast, Germany relies on centralized price determination, while covering all drugs authorized by the EMA. It limits prescription oversight to retrospective review and rare audits of physicians whose prescribing patterns fall significantly outside the clinical guidelines developed by regional physician associations. Payers do not impose prior authorization on physicians, and consumer cost sharing is limited to a maximum of 10 euros per prescription, with reductions for low-income patients and those with multiple chronic conditions. ${ }^{20}$

The Trump administration has proposed moving Medicare payment for Part B drugs from the current ASP formula, based on average net prices paid by private U.S. insurers, to an index 
of prices paid in 17 other nations, including Germany. ${ }^{2}$ This proposal has been supported by some Democratic legislators but has been opposed by some Republicans, and its political prospects are uncertain. ${ }^{21}$ Nevertheless, it highlights a bipartisan interest in reforming the U.S. pharmaceutical assessment and pricing system to benefit from the structures and experiences in other nations.

The Trump proposal estimated that a move to this "international reference pricing" could save Medicare $\$ 8.1$ billion per year on 27 high-volume Part B drugs alone. ${ }^{3}$ That estimate was based on a comparison of ASP rates with the list prices available from other nations, without accounting for off-invoice discounts and rebates. A recently published study of patient self-administered drugs covered under Medicare Part D found that the United States pays rates up to 3 times those paid by a group of 3 other high-income nations. ${ }^{22}$ A key advantage of the data used in this study, for Germany and the United States, is that they represent the actual prices paid, after accounting for all discounts and rebates. The findings do support the administration's perspective that prices currently paid in the United States are substantially higher than those paid in other nations with comparable demographic and economic characteristics.

\section{Implications for Managed Care Pharmacy}

In the United States, the decision of which drugs are included in covered formularies and which forms of prior authorization and step edits are to be required is made by each payer and purchaser separately. Pharmacists working for insurers, PBMs, specialty pharmacies, and hospitals often must make numerous coverage decisions under time pressure and without strong evidence of the comparable performance of one product relative to its therapeutic alternatives. The resulting differences in coverage and utilization management can be confusing to prescribing physicians and their patients.

The German experience shows that coverage policy can be centralized and based on better comparative clinical data, since manufacturers have incentives to provide strong evidence if they wish to negotiate an attractive net price. Germany maintains a private multipayer health insurance system and purchases many infused drugs through hospitals and hospital networks. All these organizations employ pharmacists, but these professionals are tasked with the responsibility to help physicians decide on the best treatment for individual patients rather than which drugs should be eligible for coverage. The German experience suggests that evidence-based drug pricing can support a framework of evidence-based drug access and thereby allow pharmacists to focus more on clinical and less on economic activities. ${ }^{23}$

\section{Conclusions}

The multipayer German health care system has devised a centralized process of clinical assessment and price negotiations for newly launched drugs, offering a model for the United States as it debates how best to moderate prices while sustaining patient access. As reported in this paper, the implementation by Germany of comparative clinical assessment and price negotiations led to a substantial divergence in the performance of the 2 systems, to the advantage of Germany. The ratio of U.S. to German prices for the same 80 physician-infused drugs averaged 1.3 before implementation in 2011 and subsequently rose to 1.6 by 2018. Price moderation for innovative drugs is possible. The United States needs to study approaches taken in other nations and link the prices paid here to those paid there.

\section{Authors}

FABIAN BERKEMEIER, MS, Berlin University of Technology, IGES Institute, Berlin, Germany; CHRISTOPHER WHALEY, PhD, RAND Corporation, University of California, Berkeley; and JAMES C. ROBINSON, PhD, School of Public Health, University of California, Berkeley.

AUTHOR CORRESPONDENCE: James C. Robinson, PhD, School of Public Health, University of California, Berkeley, Berkeley, CA 94720-7360.Tel.: 510.642.0564; E-mail: James.Robinson@berkeley.edu.

\section{DISCLOSURES}

This study was supported by the Commonwealth Fund, New York. The sponsor had no role in the study design, conduct, interpretation, or writing up of results. Whaley reports a grant from the National Institute on Aging, unrelated to this work. The other authors have no potential conflicts of interest to report.

\section{REFERENCES}

1. Kesselheim AS, Avorn J, Sarpatwari A. The high cost of prescription drugs in the United States: origins and prospects for reform. JAMA. 2016; 316(8):858-71

2. U.S. Department of Health and Human Services. HHS advances payment model to lower drug costs to patients. Press release. October 25, 2018. Available at: https://www.hhs.gov/about/news/2018/10/25/hhs-advancespayment-model-to-lower-drug-costs-for-patients.html. Accessed October 22, 2019

3. U.S. Department of Health and Human Services, Assistant Secretary for Planning and Evaluation. Comparison of U.S. and international prices for top Medicare Part B drugs by total expenditures. October 25, 2018. Available at: https://aspe.hhs.gov/system/files/pdf/259996/ ComparisonUSInternationalPricesTopSpendingPartBDrugs.pdf. Accessed October 22, 2019

4. Schlette S, Hess R. Early benefit assessment for pharmaceuticals in Germany: lessons for policymakers. Issue Brief (Commonw Fund). 2013;29:1-9.

5. Leverkus F, Chuang-Stein C. Implementation of AMNOG: an industry perspective. Biom J. 2016;58(1):76-88.

6. Lauenroth VD, Stargardt T. Pharmaceutical pricing in Germany: how is value determined within the scope of AMNOG? Value Health. 2017;20(7):927-35. 
7. Lauer-Fischer GmbH. The Lauer-Taxe download. 2018. [Database]. Available at: https://www.cgm.com/lauer-fischer/loesungen_lf/lauer_taxe_lf/ lauer_taxe_download_lf/lauer_taxe_download_en.de.jsp. Accessed October 22, 2019.

8. Robinson JC, Ex P, Panteli D. How drug prices are negotiated in Germany. To the Point (blog). Commonwealth Fund. June 13, 2018. Available at: https://www.commonwealthfund.org/publications/issue-briefs/2019/jan/ reference-pricing-germany-implications. Accessed October 22, 2019.

9. Henschke C, Sundmacher L, Busse R. Structural changes in the German pharmaceutical market: price setting mechanisms based on early benefit evaluation. Health Policy. 2013;109(3):263-69.

10. Köhler M, Haag S, Biester K, et al. Information on new drugs at market entry: retrospective analysis of health technology assessment reports versus regulatory reports, journal publications, and registry reports. BMJ. Published online February 26, 2015. Available at: https://www.ncbi.nlm.nih. gov/pmc/articles/PMC4353284/. Accessed October 22, 2019.

11. JC Robinson, P Ex, D Panteli. Single-payer drug pricing in a multipayer health system: does Germany offer a model for the U.S.? Health Affairs Blog. March 22, 2019. Available at: https://www.healthaffairs.org/do/10.1377/ hblog20190318.475434/full/. Accessed October 22, 2019.

12. Greiner W, Witte J, Gensorowsky D. Nutzenbewertung von Arzneimitteln in Deutschland. Schwerpunkt: Hochstpreise fur ein Mehr an Lebensqualitat? AMNOG Report 2019. Heidelberg, Germany: Medhochzwei Verlag GmbH; 2019. Available at: https://www.dak.de/dak/download/amnog-report-2019pdf-2099700.pdf. Accessed October 22, 2019.

13. The Federal Joint Committee (Gemeinsamer Bundesausschuss). Bewertungsverfahren: Nutzenbewertungen nach \& 35a SGB V. 2019. Available at: https://www.g-ba.de/bewertungsverfahren/nutzenbewertung/. Accessed October 22, 2019.

14. Werble C. Health Policy Brief: Medicare Part B. The Medicare Part B buy and bill payment structure for physician-administered drugs also influences private sector prices. Health Affairs. August 10, 2017. Available at: https:// www.healthaffairs.org/do/10.1377/hpb20171008.000171/listitem/healthpolicybrief_171.pdf. Accessed October 22, 2019.
15. Centers for Medicare \& Medicaid Services. Medicare Part B drug average sales price. 2018. Available at: https://www.cms.gov/Medicare/Medicare-Feefor-Service-Part-B-Drugs/McrPartBDrugAvgSalesPrice/index.html. Accessed October 22, 2019

16. Centers for Medicare \& Medicaid Services. Medicare Part B drug spending dashboard. 2019. Available at: https://www.cms.gov/ResearchStatistics-Data-and-Systems/Statistics-Trends-and-Reports/Information-onPrescription-Drugs/MedicarePartB.html. Accessed October 22, 2019.

17. Organisation for Economic Co-operation and Development. OECD data. Purchasing power parities (PPP). 2018. Available at: http://data.oecd.org/ conversion/purchasing-power-parities-ppp.htm. Accessed October 22, 2019.

18. Bureau of Labor Statistics. CPI-all urban consumers (current series). CUUR0000SA0 not seasonally adjusted. 2018. Available at: https://data.bls. gov/timeseries/CUUR0000SA0?output_view=pct_12mths. Accessed October 22, 2019.

19. Dimick JB, Ryan AM. Methods for evaluating changes in health care policy: the differences in differences approach. JAMA. 2014;312(22):2401-02.

20. Robinson JC, Panteli D, Ex P. Negotiating drug prices without restricting patient access: lessons from Germany. STAT. June 27, 2019. Available at: https://www.statnews.com/2019/06/27/negotiating-drug-prices-withoutrestricting-patient-access-lessons-from-germany/. Accessed October 22, 2019

21. Karlin-Smith S. The Bernie Sanders-Trump mind meld on drug costs. Politico. November 20, 2018. Available at: https://www.politico.com/ story/2018/11/20/bernie-sanders-donald-trump-drug-prices-1005764 Accessed October 22, 2019

22. Kang SY, DiStefano MJ, Socal MP, Anderson GF. Using external reference pricing in Medicare Part D to reduce drug price differentials with other countries. Health Aff (Millwood). 2019;38(5):804-11.

23. Robinson JC, Howell S, Pearson SD. Value-based pricing and patient access to specialty drugs. JAMA. 2018;319(21):2169-70. 


\section{APPENDIX Selection of Drugs for Study Sample}

Drugs were included in this study if they were available for prescription and sale in both the German and U.S. health care systems, were administered by physicians as distinct from self-administered by patients, and could be matched using Medicare's Healthcare Common Procedure Coding System (HCPCS) codes. The study inclusion and exclusion criteria are presented in the figure below:

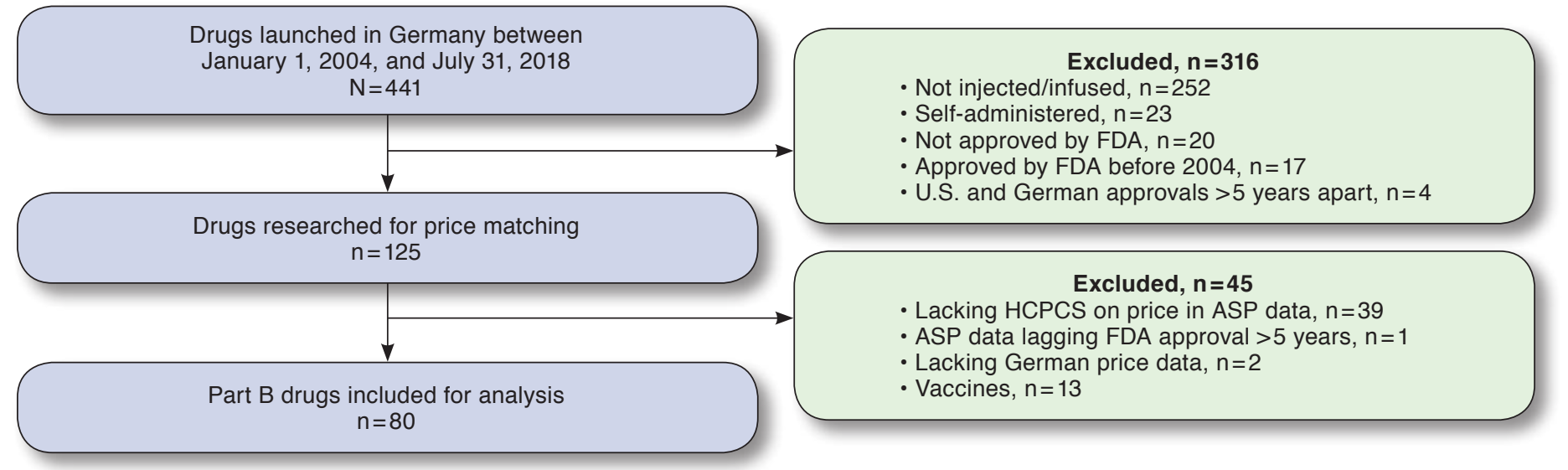

Drugs available in Germany for prescription and sale in each quarter are included in the Lauer-Taxe database, which is available to pharmacies, payers, and other entities willing to pay a nominal access fee. We used a version of the Lauer-Taxe database maintained by the IGES Institute, a consulting firm originally based at the Technical University of Berlin and now independent.

We began with all drugs launched onto the German market between January 2004 and July 2018. We excluded drugs that were not injected/ infused by physicians, since our intent was to match German data to Medicare Part B data $(n=252)$. Self-administered drugs were excluded because they are covered by Medicare Part D rather than Part $B(n=23)$.

Drugs not approved by the U.S. Food and Drug Administration (FDA) for prescription in the United States were excluded ( $\mathrm{n}=20$ ). Drugs approved by the FDA before 2004 were also excluded, since average sales price (ASP) data were only available beginning in the first quarter of 2005 and were based on private insurer paid prices 2 quarters earlier $(n=17)$. We also excluded drugs with more than 5 years between FDA approval in the United States and European Medicines Agency (EMA) approval in Germany $(n=4)$.

For the remaining 125 drugs, we researched the Medicare Part B data files and Lauer-Taxe German price data for matches. ASP and crosswalk files from the first quarter of 2005 through the fourth quarter of 2018 were searched for active substance name and relevant fractions of active substance name. Matches were verified by product name and route of administration.

We excluded drugs lacking an HCPCS code or price data in the ASP database $(n=39)$. Because we analyzed prices at launch and developments thereafter, we excluded 1 drug with more than 5 years lag between FDA approval and first Medicare ASP data. We also excluded drugs lacking price data in the German Lauer-Taxe database $(n=2)$. Finally, we excluded vaccines because pricing in Germany is negotiated with manufacturers by individual sickness funds and not published in the Lauer Taxe database $(n=13)$.

The final study sample included 80 physician-administered products approved, priced, and available for sale in both Germany and the United States. Of the total, 41 had been launched in Germany after the implementation of the comparative effectiveness and collective negotiations process in 2011; 4 of these are used exclusively in the inpatient hospital setting. Thirty-nine drugs were launched on the German market before 2011 and were not subject to collective negotiations. 